\title{
Commentary: Measuring the performance in real time
}

\author{
Stephanie N. Nguyen, MD, and \\ Hiroo Takayama, MD, PhD
}

Although simple in theory, septal myectomy (SM) remains among the most challenging and perhaps one of the most underappreciated cardiac operations currently performed, with the reasons for this being multifactorial. The procedural challenges lie in the limited visualization of the transaortic surgical field, as well as in the highly variable anatomy and fluid dynamics, involving the mitral valve and subvalvular apparatus. The extent of the myocardial resection in terms of depth and width is dependent on the subjective judgment of the surgeon. These challenges are further exacerbated by the steep learning curve and low surgical volume in most centers, and, as a result, most cases are performed by only a handful of experts. ${ }^{1}$ This underscores the importance of specialized training and mentorship, as well as simulation and models recently described. ${ }^{2,3}$ Furthermore, the recognized variability of surgical quality and the limited availability of expert surgeons have contributed to the increasing interest and investment in alcohol septal ablation for patients with obstructive hypertrophic cardiomyopathy, despite the reported excellent outcomes of SM.,

If the surgical procedure could become more straightforward and reproducible, many of the aforementioned obstacles could be mitigated. In this issue, Williams and colleagues $^{5}$ describe their experience with intracardiac echocardiography during cardioplegic myocardial arrest in 10 consecutive SM procedures for hypertrophic cardiomyopathy. In this technique, termed on-pump intraoperative echocardiography, a unique ultrasound probe is

\footnotetext{
From the Division of Cardiac, Thoracic and Vascular Surgery, Department of Surgery, Columbia University, New York, NY.

Disclosures: The authors reported no conflicts of interest.

The Journal policy requires editors and reviewers to disclose conflicts of interest and to decline handling or reviewing manuscripts for which they may have a conflict of interest. The editors and reviewers of this article have no conflicts of interest.

Received for publication Dec 18, 2019; revisions received Dec 18, 2019; accepted for publication Jan 3, 2020; available ahead of print Feb 23, 2020.

Address for reprints: Hiroo Takayama, MD, PhD, 707 Fort Washington Ave, New York, NY 10032 (E-mail: ht2225@cumc.columbia.edu).

JTCVS Techniques 2020;2:68-9

2666-2507

Copyright $@ 2020$ The Authors. Published by Elsevier Inc. on behalf of The American Association for Thoracic Surgery. This is an open access article under the CC BY-NCND license (http://creativecommons.org/licenses/by-nc-nd/4.0/).

https://doi.org/10.1016/j.xjtc.2020.01.026
}

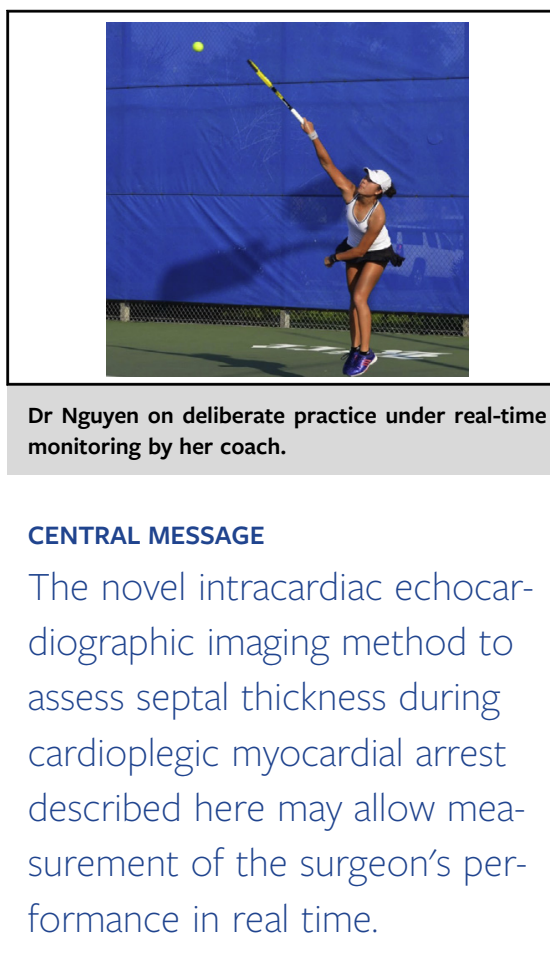

placed transaortically on the septum during myectomy surgery, and the septal thickness is measured. Williams and colleagues $^{5}$ are to be congratulated on their innovative leverage of existing ultrasonographic technology, with the goal of aiding in the conduction of a complex and highrisk procedure in real time. Because this technique is still in its infancy, Williams and colleagues have yet to determine exactly how to utilize it in guiding septal resection; however, this study shows promising preliminary findings regarding the utility of on-pump intraoperative echocardiography for real-time quantification of septal thickness before, during, and after SM with the heart under cardioplegic arrest. The idea of using ultrasound technology during SM comes relatively naturally to cardiac surgeons. Having tested a variety of available ultrasound devices, including epicardial ultrasonography, an epiaortic hockey stickshaped ultrasound probe, and transesophageal echocardiography (through a conventional transesophageal view with the heart filled with blood and by inserting the probe through the aortic valve in the surgical field [!]), with little meaningful success, we see great potential in using this long, narrow ultrasound probe for continuous verification of the location and extent of resection, allowing surgeons to identify residual areas of septal hypertrophy. Moreover, on-pump intraoperative echocardiography may provide a unique opportunity for less experienced surgeons and 
trainees to develop a greater understanding of the heterogeneous anatomy, as well as to perform SM in a controlled environment under the careful supervision of expert surgeons.

Although real-time performance measure with constant feedback is the model of traditional teaching for surgical procedures just as in sports, it has been very challenging in SM. Development of more technology of this kind should be encouraged.

\section{References}

1. Maron BJ, Rastegar H, Udelson JE, Dearani JA, Maron MS. Contemporary surgical management of hypertrophic cardiomyopathy, the need for more myectomy surgeons and disease-specific centers, and the Tufts initiative. Am J Cardiol. 2013;112:1512-5.

2. Hermsen JL, Yang R, Burke TM, Dardas T, Jacobs LM, Verrier ED, et al. Development of a 3-D printing-based cardiac surgical simulation curriculum to teach septal myectomy. J Thorac Cardiovasc Surg. 2018;156: 1139-48.e3.

3. Chiang YP, Ginns JN, Takayama H. Use of cutting-edge technology to learn myocardial cutting edge in septal myectomy. J Thorac Cardiovasc Surg. 2018; 156:1149-50

4. Hodges K, Rivas CG, Aguilera J, Borden R, Alashi A, Blackstone EH, et al. Surgical management of left ventricular outflow tract obstruction in a specialized hypertrophic obstructive cardiomyopathy center. J Thorac Cardiovasc Surg. 2019; 157:2289-99.

5. Williams DM, Nampi RG, Saric M, Grossi EA, Sherrid MV, Swistel DG On-pump intracardiac echocardiography during septal myectomy for hypertrophic cardiomyopathy. J Thorac Cardiovasc Surg Tech. 2020; 2:60-6. 